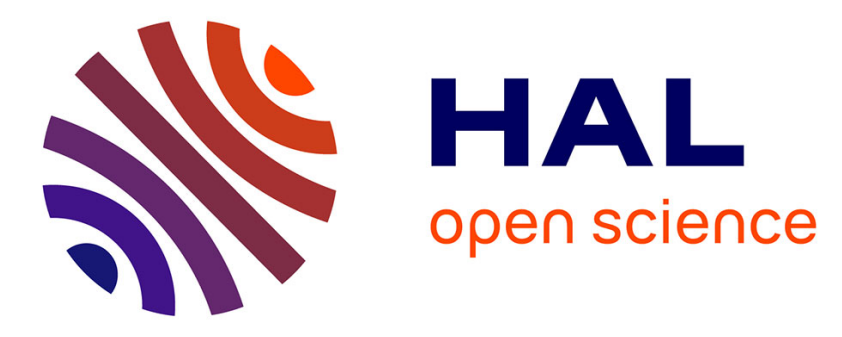

\title{
Analysis of monoclonal antibody by a novel CE-UV/MALDI-MS interface
}

Michael Biacchi, Ricky Bhajun, Nassur Saïd, Alain Beck, Yannis Nicolas Francois, Emmanuelle Leize-Wagner

\section{- To cite this version:}

Michael Biacchi, Ricky Bhajun, Nassur Saïd, Alain Beck, Yannis Nicolas Francois, et al.. Analysis of monoclonal antibody by a novel CE-UV/MALDI-MS interface. Electrophoresis, 2014, 35 (20), pp.2986-2995. 10.1002/elps.201400276 . hal-01993518

\section{HAL Id: hal-01993518 https://hal.science/hal-01993518}

Submitted on 24 Jan 2019

HAL is a multi-disciplinary open access archive for the deposit and dissemination of scientific research documents, whether they are published or not. The documents may come from teaching and research institutions in France or abroad, or from public or private research centers.
L'archive ouverte pluridisciplinaire HAL, est destinée au dépôt et à la diffusion de documents scientifiques de niveau recherche, publiés ou non, émanant des établissements d'enseignement et de recherche français ou étrangers, des laboratoires publics ou privés. 


\title{
Analysis of monoclonal antibody by a novel CE- UV/MALDI-MS interface
}

\author{
Michael Biacchi ${ }^{1}$, Ricky Bhajun ${ }^{1}$, Nassur Saïd ${ }^{1}$, Alain Beck ${ }^{2}$, Yannis Nicolas François ${ }^{1}$ and \\ Emmanuelle Leize-Wagner ${ }^{1}$
}

1 Laboratoire de Spectrométrie de Masse des Interactions et des Systèmes (LSMIS), CNRS UMR 7140, Université de Strasbourg, Strasbourg, France.

2 Centre d'immunologie Pierre Fabre; Saint-Julien-en-Genevois, France

\begin{abstract}
Monoclonal antibodies (mAb) are highly complex proteins that advertise a wide range of microheterogeneity that requires multiple analytical methods for full structure assessment and quality control. As a consequence, the characterization of mAbs on different levels is particularly product - and time - consuming. Capillary Electrophoresis-Mass Spectrometry (CE-MS) couplings, especially to matrix-assisted laser desorption/ionization (MALDI) appear really attractive methods for the characterization of biological samples. In this work, we report on the last instrumental development and performance of the first totally automated off-line CE-UV/MALDI-MS/MS. This interface is based on the removal of the original UV cell of the CE apparatus, the modification of the spotting device geometry and the creation of an integrated delivery matrix system. The performance of the method was evaluated with separations of 5 intact proteins and a tryptic digest mixture of 9 proteins. Intact proteins application shows the acquisition of electropherograms with high resolution and high repeatability. In the peptide mapping approach, a total number of 154 unique identified peptides were characterized using MS/MS spectra corresponding to average sequence coverage of $64.1 \%$. Comparison with NanoLC/MALDI-MS/MS showed complementarity at the peptide level with an increase by $42 \%$ when using CE/MALDI-MS coupling. Finally, this work represents the first analysis of intact mAb charge variants by capillary
\end{abstract}


zone electrophoresis using a MS detection. Moreover, using a peptide mapping approach CEUV/MALDI-MS/MS fragmentation allowed 100\% sequence coverage of the light chain and $92 \%$ on the heavy chain and the separation of the 4 major glycosylated peptides and their structural characterization.

\section{Introduction}

The characterization of complex protein and peptide mixtures represents one of the biggest challenge in many research fields such as biological [1-3] or biopharmaceutical sciences [4-5]. Since 1986 and the approbation of Muromonab-CD3 by the Food and Drug Administration (FDA), monoclonal antibodies (mAbs) have taken a major market share in the pharmaceutical industry and their development is constantly increasing [6-7]. mAbs are particularly interesting because they have good therapeutic efficiency, favorable pharmacokinetic and pharmacodynamics, and lead to reduction of side-effects [8]. mAbs are highly complex glycoproteins potentially displaying many naturally-occurring molecular micro-heterogeneities combined with imperfect processing. There is a continuous need for analytical methods improvement to be ultimately able to provide a fast and accurate characterization. Today, the method of choice for the identification of proteins and peptides is the mass spectrometry (MS) [9] generally coupled with separation techniques such as high-performance liquid chromatography (HPLC) or gel electrophoresis. Technically, HPLC-MS is the most widely used coupling thanks to its high reproducibility and its great resolution but also especially for the relative ease of coupling with a fraction collector device or directly in the source of a mass spectrometer. As an alternative to HPLC, capillary electrophoresis (CE) has been demonstrated to be a useful and powerful separation method for the characterization of charged and neutral molecules [10-12]. Advantages of CE are fast separation, high efficiency and high resolution. However, properties of $\mathrm{CE}$ such as an ultralow flow rate, a background electrolyte (BGE) that can be highly salted, and the necessity of maintaining the electric field during the separation make the CE-MS coupling more difficult to implement [13-14]. Nevertheless, despite these technical aspects, the hyphenation of CE to MS appears as a very attractive coupling allowing to perform significant advances in many research areas such as proteomics [15-16], metabolomics [17] and intact proteins characterization [18-19]. Since the end of the 80s, a large number of CEMS interfaces has been developed. Due to the direct coupling property, most innovation have been realized on the coupling between CE and electrospray ionization (ESI) [20] by sheath-flow [21- 
22], liquid-junction [23-24], or sheathless [25-26] interfaces. However, the nature of the BGE (presence of salts, volatility) can affect the stability of the spray and then limits the number of BGE which does not prevent the performances of MS. Matrix-assisted laser desorption/ionization time of flight MS (MALDI-TOF-MS) is a MS technology which presents a greater tolerance to the presence of salts or surfactants [22]. Moreover, hyphenation of electrophoretic methods with MALDI-MS allows easily to detect in positive and negative modes in MS. Then, as an interesting alternative to CE/ESI-MS, a great number of CE/MALDI-MS interfaces have been developed [2743]. The first strategy to hyphenate electrophoretic method with MALDI-MS has consisted to develop on-line interface [30-32]. However, because of sample is first dried on a solid surface before insertion into the MALDI source, heavy instrumental development appeared as one of the most significant issue for the implementation of this interface. The second option consisted to promote the off-line coupling using CE collection fractions on a MALDI plate. This strategy opens the way to sample treatment directly on the plate such as enzymatic digestion [44] or enrichment [45]. Concerning the deposit process, majority of the existing interfaces used a T-junction with sheath-flow [33-39]. More recently sheathless interfaces have been developed. In 2008, Wang et al. have realized an interface based on the use of a junction liquid which allows to eliminate the addition of the sheath liquid [42]. In 2009, Busnel et al. have designed an iontophoretic fraction collection approach to avoid the sheath-flow and the possible suction effect [43]. However, one of the interface drawbacks is having to fill little reservoir on the plate before deposit process. This prevents automation and high-throughput analysis. Concerning fraction collection devices, only one commercial system is compatible with CE/MALDI-MS [37]. However, this interface is originally designed for HPLC/MALDI-MS coupling and presents some geometry drawbacks for CE/MALDI-MS such as the minimum length of the capillary. At the same time, homemade robotic systems have been developed, such as electrospray [40] or inkjet spotting [41]. Meanwhile, since 2001 interfaces between MALDI-MS and microfluidic devices have been developed [46]. The easiest strategy was reported to carry out CE separation in an open channel, where the separated analytes were directly ionized from the open channel to a mass spectrometer [47-48]. However, the open channel was filled by gel to suppress electroosmotic flow (EOF) and reduce analyte dispersion after the CE separation. In that case, only capillary gel electrophoresis is applicable. Then this strategy is not possible to regular free-solution CE modes including CZE. 
The efficiency and the robustness of these interfaces have been reported, but none of these systems allows the automation. Most off-line CE/MALDI-MS coupling do not possess a second detection systems to control the separation. Few interfaces used an additional external UV system which made the methodology more expensive and made difficult the automation with the development of synchronized software [35-36].

In this work we have developed the first totally automated off-line CE-UV/MALDI-MS/MS with integrated delivery matrix system. Based on different homemade modifications performed on a commercial CE device and a fraction collection system, we introduced a totally automated approach to make protein separation and peptide mapping strategy. In order to control the $\mathrm{CE}$ separation, the original UV cell of the CE apparatus was deported to allow the simultaneous UV detection and fraction collection without external UV system. Modification of the spotting device geometry allowed to reduce the total capillary length. Based on the properties of the CE apparatus to apply simultaneously a pressure and a power supply, and the modification on the external cartridge, an integrated homemade delivery matrix system was developed to be universally compatible in terms of MALDI deposition types. The performance of the method was evaluated with the separations of five intact proteins and a tryptic digest mixture of nine proteins. Finally, in order to confirm the performances of the system for the characterization of mAbs, application to the separation of intact $\mathrm{mAb}$ and bottom up approach have been realized using the CEUV/MALDI-MS interface.

\section{Materials and methods}

2.1 Chemicals and Materials. All chemicals used were of analytical grade or high purity grade and purchased from Sigma-Aldrich (Saint Louis, MO, USA). Water used to prepare buffers and sample solutions was obtained using an ELGA purelab UHQ PS water purification system (Bucks, UK). Cytochrome c (Cyt c), ribonuclease A ((RNase A), $\alpha$-lactalbumin ( $\alpha$ Lac), insulin (Ins), myoglobin (Myo), bovine serum albumin (BSA), lysozyme (Lys), $\beta$-Casein ( $\beta$ Cas), carbonic anhydrase II (CAII) were obtained from Sigma-Aldrich (Saint Louis, MO, USA). Trypsin (modified, sequencing grade) was purchased from Promega AG (Dübendorf, Switzerland). 
2.2 Standard protein mixtures. For intact protein study, a standard protein solution of $\alpha$ Lac (14.2 kDa), RNase A (13.6 kDa), Cyt c (12.3 kDa), Lys (14.3 kDa) and Myo (16.9 kDa) were prepared in Water at $120 \mathrm{nM}, 50 \mathrm{nM}, 40 \mathrm{nM}, 40 \mathrm{nM}$ and $50 \mathrm{nM}$ respectively.

2.3 Tryptic digestion procedure. Tryptic digests of protein solution were prepared using sequence-grade trypsin $(1: 10 \mathrm{w} / \mathrm{w})$. Before digestion, each protein was diluted to a concentration of $3 \mu \mathrm{M}$ in $1 \%$ formic acid. Dithiothreitol (DTT) was then added to the protein solution at a final concentration of $10 \mathrm{mM}$. The mixture was incubated for 5 minutes at $95^{\circ} \mathrm{C}$, then cooled to ambient temperature. Then, Iodoacetamide (IAM) $100 \mathrm{mM}$ was added at a final concentration of $20 \mathrm{mM}$ and the mixture was placed in the dark for 20 minutes. $10 \mu \mathrm{L}$ of trypsin was added and the mixture was incubated at room temperature for 3 hours; additional $10 \mu \mathrm{L}$ of trypsin were added to the sample for overnight digestion at room temperature. This solution was then analyzed directly by CE/MALDI-MS without any further purification step. Amounts of protein tryptic digests with 300 fmol of each proteins were injected.

2.4 Capillary Electrophoresis. The $\mathrm{CE}$ experiments were carried out on a $\mathrm{P} / \mathrm{ACE} \mathrm{MDQ}^{\mathrm{TM}} \mathrm{CE}$ system from Beckman Coulter (Brea, CA) equipped with a temperature controlled autosampler and a power supply able to deliver up to $30 \mathrm{kV}$. A $32 \mathrm{Karat}^{\mathrm{TM}}$ (Beckman Coulter, Brea, CA) was used for instrument control, data acquisition and data handling. Polymicro bare fused-silica capillaries of $50 \mu \mathrm{m}$ i.d. were obtained from Photonlines (St-Germain-en-Laye, France). Concerning modified capillaries, capillaries were coated in laboratory with hydroyxypropylcellulose (HPC) following the protocol described by Shen et al. [49]. For model protein separation, 83.3mM ionic strength ammonium acetate ( $\mathrm{pH}$ 4.0) has been used as BGE. Samples were introduced into the capillary by electrokinetic injections $(3 \mathrm{kV}, 8 \mathrm{~min})$, and the separation of proteins was performed by applying $20 \mathrm{kV}$ across the capillary. For intact mAbs separation, $400 \mathrm{mM} \varepsilon$-Amino-caproic acid (EACA)acetic acid, $0.05 \% \mathrm{~m} / \mathrm{v}, \mathrm{pH} 5.7$ has been used as BGE. For peptide mapping approach, solution of $1 \%$ formic acid and ammonium acetate $(\mathrm{pH} 9.3,935 \mathrm{mM}$ ionic strength) were used in CE as background electrolyte (BGE) and leading electrolyte (LE), respectively [50]. Except for the model proteins separation, injection volumes have been calculated using CEToolbox application (Pansanel, GooglePlay). 
2.5 Nano-HPLC. Protein digests were analyzed using an UltiMate 3000 nano-HPLC system (Dionex, Germering, Germany) coupled to a Proteineer FC (Bruker Daltonics, Bremen, Germany). A Pepmap100 C18 column (Dionex, Germering, Germany) was used. The gradient (solvent A, $0.1 \%$ trifluofoacetic acid (TFA); solvent B, $0.1 \%$ TFA in $80 \%$ acetonitrile) was as follows: $0-4$ $\min , 4 \% \mathrm{~B}$; 4-32 $\min , 4-55 \%$ B; $32-34 \mathrm{~min}, 55-90 \% \mathrm{~B}$; $34-40 \min 90 \% \mathrm{~B}$; 40-45 min, 90-4\% B; $45-65 \mathrm{~min}, 4 \% \mathrm{~B}$. A flow rate of $300 \mathrm{~nL} / \mathrm{min}$ was applied. The sample injection volume was $1 \mu \mathrm{L}$.

2.6 CE/MALDI-MS Interface. Automated off-line coupling of CE to MALDI-MS was performed by using a homemade modified automatic spotting device, Proteineer FC (Bruker Daltonics, Bremen, Germany) for the sheath flow-assisted spotting from the CE capillary end onto a MALDI target. The capillary outlet was positioned inside a fixed steel needle, being a modified part of a robotic $x-y-z$ axis motion system. The original set-up delivered from Bruker Daltonics was modified by us in order to reduce the distance between CE output and the MALDI target. This change has consisted to shift the original steel needle close to $\mathrm{CE}$ output and has reduced the minimum total capillary length from $110 \mathrm{~cm}$ to $60 \mathrm{~cm}$. At the upper end of the needle a cross connection was fitted. On one side of the cross, the sheath liquid, which is the separation BGE, was supplied by means of the syringe-pump included in the Proteineer FC (Bruker Daltonics, Bremen, Germany) and on the other side, the ground was connected. The steel needle functioned as an electrode for the $\mathrm{CE}$ and the current was maintained by a liquid junction between the steel needle and the end of the capillary (Fig. 1). During CE separation, the emerging droplet of CE effluent and sheath liquid made contact with the MALDI target. The original set up of the UV cell in the $\mathrm{P} / \mathrm{ACE} \mathrm{MDQ}^{\mathrm{TM}}$ (Beckman Coulter, Brea, $\mathrm{CA}$ ) was modified in order to allow the simultaneous UV detection near the outlet of the capillary and fraction collection (Fig. 1). A homemade UVwindow compatible with P/ACE MDQ system (Beckman Coulter, Brea, CA) was mounted at the upper of the cross connection. Using three optical fibers with one couple connected in pairs, UVdetection was deported out of the $\mathrm{CE}$ instrument without instrumental modification and without additional UV spectrometer. Therefore, for CE with fraction collection, a capillary with the UV detection window positioned $10 \mathrm{~cm}$ from the $\mathrm{CE}$ capillary end was used. 


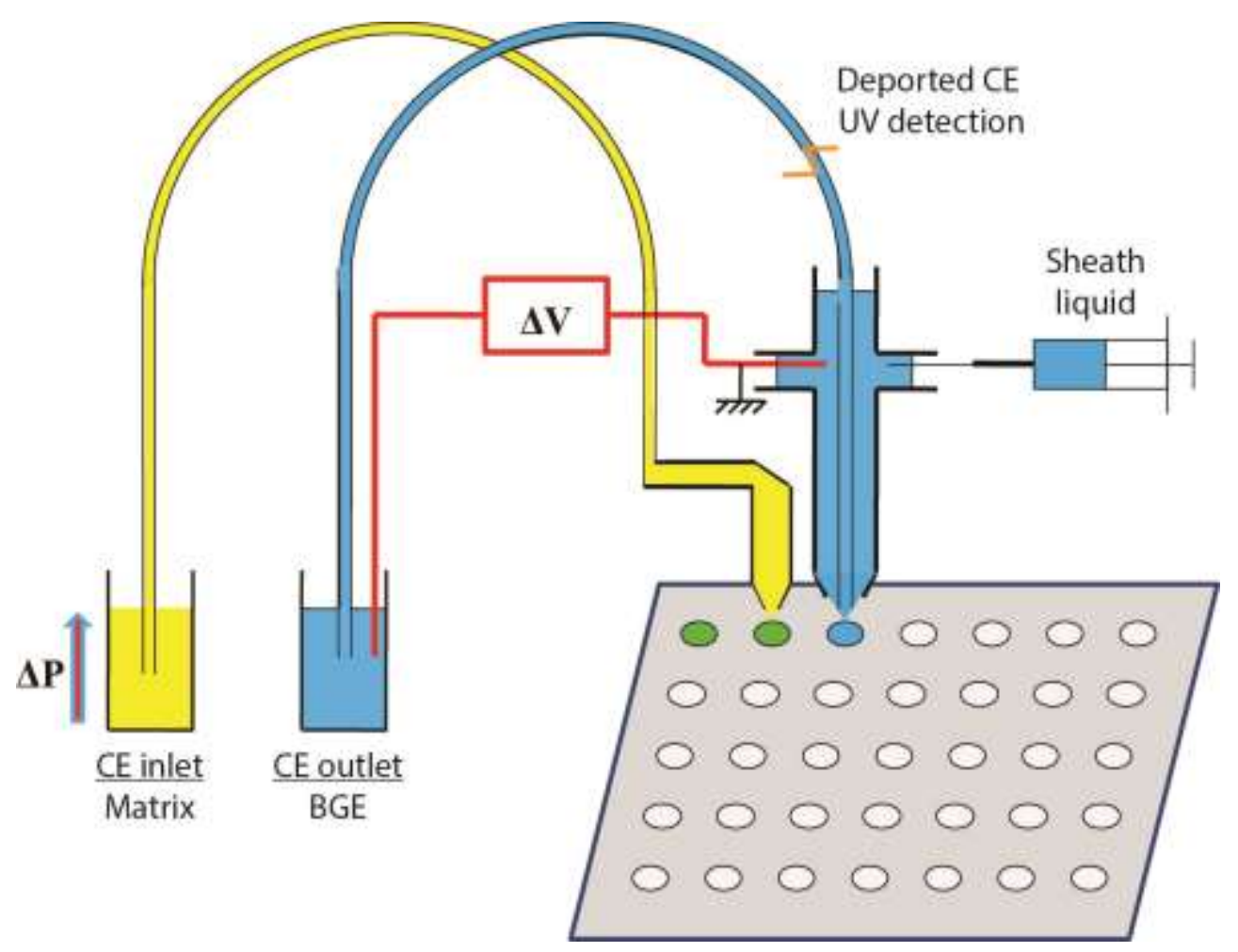

\section{Figure 1.}

Schematic representation of the experimental set up of the CE-UV/MALDI-MS interface including the deported UV detection and the integrated delivery matrix system.

In order to be universally compatible in terms of MALDI deposition types, a homemade delivery matrix system was developed to add the matrix just after sample deposition allowing dried droplet fraction collection directly onto the MALDI target. The matrix interface consisted of a second steel needle surrounding the matrix capillary $(100 \mathrm{~cm}$ total length, $100 \mu \mathrm{m}$ i.d.) in the form of a coaxial tube. Matrix capillary end was placed at a distance of 5 millimeters from CE capillary end corresponding to the distance between two consecutive spots of a MALDI targed provided by Bruker Daltonics. To avoid the use of an additional syringe pump to deposit the matrix, a modification was made on the external cartridge delivered by Beckman Coulter. The external extremity of the cartridge was pierced to allow the setup of a second capillary. Separation and matrix capillaries were then placed in the external cartridge and positioned in the $\mathrm{CE}$ inlet for matrix capillary and the $\mathrm{CE}$ outlet for separation capillary. Properties of P/ACE MDQ ${ }^{\mathrm{TM}}$ (Beckman Coulter, Brea, CA) allowing to applied at the same time a pressure and a power supply allowed performing simultaneously CE separation while delivery matrix. The interface is also compatible 
with a thin layer deposition types. In that case, matrix capillary was removed. Hystar 3.2 (Bruker Daltonics, Bremen, Germany) was used for Proteineer FC control.

2.7 MALDI-TOF-MS and MALDI-TOF-TOF MS/MS. For intact protein and intact $\mathrm{mAb}$ separations, the matrix was prepared by dissolving 2,5-dihydroxybenzoïque (DHB) $\left(2 \mathrm{~g} . \mathrm{L}^{-1}\right)$ in $0.1 \%$ trifluoroacetic acid/acetonitrile (TFA/ACN) (50/50). Fraction collection fraction was realized using Ground Steel MALDI target (Bruker Daltonics, Bremen, Germany). For peptide mapping approach, $\alpha$-cyano-4-hydroxycinnamic acid (CHCA) (5g/L) matrix was prepared following the classical AnchorChip protocol provided by Bruker Daltonics. Fraction collection was realized using AnchorChip MALDI target (Bruker Daltonics, Bremen, Germany). When the samples were directly collected on a MALDI target with $0.6 \mu \mathrm{L}$ sheath liquid, $0.6 \mu \mathrm{L}$ of the matrix solution were automatically deposited on the same spot.

Mass spectra of the CE fractions were recorded using an Autoflex III MALDI-TOF (Bruker Daltonics, Bremen, Germany), operating in reflector mode and with FlexControl software. Positively charged ions were detected and sums of 1500 single-shot spectra were acquired automatically from each sample by using the AutoXecute software. For peptide mapping study WarpLC 1.2 software was used. Data processing was performed with FlexAnalysis 3.0 and Biotools 3.2 provided by the mass spectrometer manufacturer. All spectra were calibrated according an external calibration using Protein calibration standard I (Bruker Daltonics, Bremen, Germany) for intact protein separation and Peptide calibration standard II (Bruker Daltonics, Bremen, Germany) for peptide mapping study. Data obtained from CE-MALDI-MS/MS experiments were processed using Mascot search algorithm developed by Matrix Science (Boston, MA, USA).

\section{Results and discussion}

\subsection{Evaluation of the CE-UV/MALDI-MS interface.}

CE-UV/MALDI-MS interface has been evaluated in terms of repeatability and robustness following the optimized separation conditions described by the team of Prof. Girault [51]. As a first step, we have evaluated the external UV detection (Fig. 1) by studying the repeatability in terms of migration time, peak area and resolution, of a standard protein separation in CE/MALDI- 
MS configuration. This is a significant parameter to determine if the developed system is adapted to $\mathrm{CE}$ collection. Indeed, especially for the coupling between CE and MALDI-MS, the off-line nature requires a second detection system to control the separation and then to approve the fraction collection. Moreover, an electropherogram obtained with the external UV detection as a control allowed optimizing the spotting process in terms of deposit window and deposit time interval. A neutral coated capillary has been used with a standard protein mixture, containing $\alpha$ Lac, RNase A, Cyt c, Lys and Myo at 120nM, 40nM, $50 \mathrm{nM}, 50 \mathrm{nM}$ and 40nM respectively. Samples were introduced into the capillary by electrokinetic injections ( $3 \mathrm{kV}, 8 \mathrm{~min})$, and the separation of proteins was performed by applying $20 \mathrm{kV}$ across the capillary. No fraction collection has been made (Fig. 2a); CE capillary tip was positioned in the external BGE vial placed on the Proteineer FC (Bruker Daltonics, Bremen, Germany). In order to avoid Joule heating effect during the separation, the length of the cartridge tubing was optimized to perform thermostated capillary until the UV cell. The UV detection window is located at $10 \mathrm{~cm}$ from the outlet when the total length of the capillary is $60 \mathrm{~cm}$. In term of migration time, peak area and resolution, obtained RSD $(\mathrm{n}=4)$ are less than $0.5 \%, 2.5 \%$ and $3 \%$ respectively. In addition, we have calculated signal-to-noise ratio ranging from 6 to 52. These results confirm that the externalization of the UV detection allows acquiring electropherograms with good quality, high repeatability and a good robustness. In addition this confirms the good stability of the HPC coating during the separation. Information concerning migration times allows defining the window of fraction collection, and assessing time interval for each deposit. These results confirm the possibility of obtaining CE-UV/MALDI-MS coupling without heavy instrumental development and without using an additional external UV detector. In addition, due to the use of single software to control CE apparatus, this UV modification contributes to strengthening the totally automated aspect of the coupling.

As a second step, in order to evaluate the impact of the spotting process on the separation, we have studied with the external UV detection the evolution of resolution and efficiency of the same standard protein mixture separation with fraction collection. For direct deposit on a MALDI plate, fraction collection window has been defined between 15 and 36 minutes and a spotting time interval of $30 \mathrm{~s}$ has been chosen. 

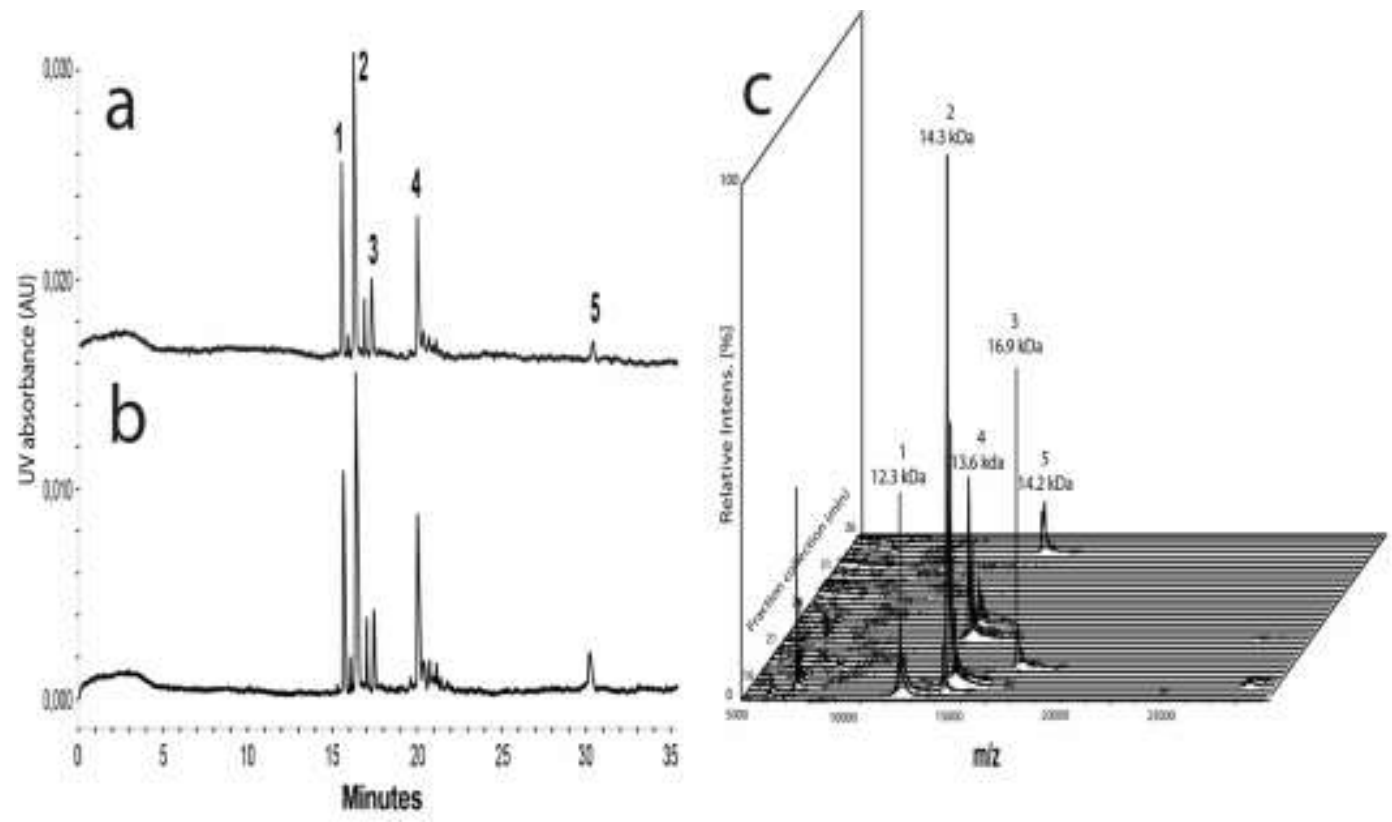

\section{Figure 2.}

UV Electropherogram without (a) and with fraction collection (b) and the corresponding MS spectra of each fraction (c) of a five protein sample by CE-UV/MALDI-MS. Experimental conditions: HPC coated capillary, $50 \mu \mathrm{m}$ d.i. x $60 \mathrm{~cm}$ (detection cell, $60 \mathrm{~cm}$ ); BGE: 83.3mM ionic strength ammonium acetate ( $\mathrm{pH} 4.0$ ); Voltage: $20 \mathrm{kV}$; Temperature: $25^{\circ} \mathrm{C}$; UV Detection: $200 \mathrm{~nm}$; Injection: 3 kV, 8 min; Sample: (1) 40 nM Cyt c, (2) 40 nM Lys, (3) 50 nM Myo, (4) 50 nM RNase A and (5) $120 \mathrm{nM} \alpha \mathrm{Lac}$ in water, MS Experimental conditions: See Experimental.

To prove the automated spotting process, Fig. 2 shows the UV electropherograms with (Fig.2b) and without (Fig. 2a) fraction collection and in the case of collection the representation of the experimental fraction using MS spectra of each spotting position.

Concerning the deposition process, UV electropherogram (Fig.2b) shows a preservation of the resolution and efficiency as compared to the separation without fraction collection (Fig. 2a). The steel needle served as outlet electrode for the CZE. Liquid junction between steel needle and capillary tip maintained electrical current. Then, even if the steel needle moves on the $z$ axis to reposition the capillary tip from a spotting position to the next, no current breakdown takes place throughout the separation and then electromigration never stops during the analysis. The localization of each protein, represented in the Fig. 2c, shows a time shift between the UV detection and the spotting process. This is totally in agreement by the fact that UV detection is located at 10 
$\mathrm{cm}$ from the capillary outlet. Moreover, offsets in time, between 1 minute for Cyt $\mathrm{c}$ and 4-5 minutes for $\alpha$ Lac, can be explained by the difference of protein effective mobilities described by the equation:

$$
\mu_{e f f}=\frac{\mathrm{Ll}}{\mathrm{tV}}
$$

with $\mu_{\text {eff }}$ the effective mobilities, $L$ and 1 the total capillary length and length to detection window, respectively, $\mathrm{V}$ the applied voltage and the migration time.

For example for RNase A, a time shift of $3 \mathrm{~min}$ between detection time (20 min) and spotting time (23 min) correspond to a value of $\mu$ eff $=12.9 .10^{-5} \mathrm{~cm}^{2} . \mathrm{V}^{-1} \cdot \mathrm{s}^{-1}$. Good agreement between time shift values and effective mobilities showed that the interface does not induce any significant suction effect. This confirms the use of a sheath liquid junction. Under these experimental conditions, it appears that the automated interface supports intact protein separations. In addition, flexibility of spotting parameters (spotting interval, sheath liquid flow rate...) combine with UV control electropherogram allow high possibility of optimization as function of the sample complexity.

\subsection{Evaluation of the CE-UV/MALDI-MS/MS for peptide mapping approach}

Peptide mapping is essential for the characterization of a complex mixture of digested proteins. In comparison to peptide mass fingerprinting (PMF), MS/MS peptide identification is not only based on digested peptide $\mathrm{m} / \mathrm{z}$ ratio measure, but also on the fragmentation of those peptides, increasing the confidence of the identification. WarpLC 1.2 (Bruker Daltonics, Bremen, Germany) is a software initially dedicated to perform peptide mapping strategy using off-line coupling between HPLC and MALDI-MS/MS. This software is fully compatible and could be easily

adapted to the CE-UV/MALDI-MS/MS approach. Due to the complexity of biological samples, a low carryover may involve the presence of the same $\mathrm{m} / \mathrm{z}$ ratio in two or three adjacent spots. In that case, the software selects the spot with the most intense $\mathrm{m} / \mathrm{z}$ parent ion to perform MS/MS. After MS/MS spectra acquisition, WarpLC 1.2 proceeds to the exclusion of the same $\mathrm{m} / \mathrm{z}$ parent ion present in the adjacent spots. The software allows a drastic reduction in the possible redundant peptides and improves the number of selected $\mathrm{m} / \mathrm{z}$ ratios which increase the number of possible unique peptides. 
To further characterize the fraction collection interface, $100 \mathrm{~nL}$ of a peptide mixture sample containing the tryptic digests of $\beta$ Cas, RNase A, CAII, BSA, Lys, Ins, Cyt c, $\alpha$ Lac and Myo (each at $3 \mu \mathrm{M}$ ) has been analyzed. Amounts of protein tryptic digests with $300 \mathrm{fmol}$ of each proteins were injected. In this study, a neutral coated capillary has been used and a transient isotachophoresis (t-ITP) preconcentration step has been implemented. For its compatibility with MALDI-MS, we used ammonium acetate (pH 9.3; 935mM ionic strength) as the leading electrolyte (LE) as in the Busnel et al. study [50]. Prior to the sample injection, a short zone of LE has been injected to allow t-ITP phenomena. A first separation without collection fraction allowed with UV electropherogram to fix the spotting parameters. At the beginning of the separation, for 25 minutes, the capillary tip was positioned in the external BGE vial placed on the Proteineer FC (Bruker Daltonics, Bremen, Germany). According to electropherogram, during this time no peptide has been detected by the UV. Fraction collection began after 25 minutes with spotting intervals of 30 s. In order to perform MS/MS, a dried droplet deposition protocol has been involved. Using the homemade delivery matrix system, CHCA matrix was placed in the inlet position of P/ACE $\mathrm{MDQ}^{\mathrm{TM}}$ system (Beckman Coulter, Brea, $\mathrm{CA}$ ) and delivered by a second capillary with a flow rate of $1.2 \mu \mathrm{L} / \mathrm{min}$ in accordance to deposit $0.6 \mu \mathrm{L}$ per spot. To determinate the exact value of the pressure to perform $1.2 \mu \mathrm{L} / \mathrm{min}$, we followed the protocol described by Gahoual et al [3]. The separation was stopped after $65 \mathrm{~min}$. A total of 80 fractions have been collected.

In order to evaluate the strength of the present CE-UV/MALDI-MS/MS coupling, the same 9 proteins digest loading amounts (300 fmol of each protein) were applied for both NanoLC/MALDIMS/MS and direct MALDI-MS. For LC-MS/MS analysis, NanoLC coupled with the same spotting device was used. Sample were separated onto a reverse phase C18 analytical column for a $65 \mathrm{~min}$ gradient and deposited on the MALDI target with a 30s spotting intervals. Dried droplet deposition protocol has been performed in order to be similar to CE-MS/MS analysis. For direct MALDI-MS deposition, a 9 proteins mixture (each at $300 \mathrm{fmol}$ ) without separation process has been deposited in the same MALDI target using the same dried droplet protocol. Table 1 summarizes the number of unique identified peptides and the sequence coverage for each protein using CE-UV/MALDIMS/MS, NanoLC/MALDI-MS/MS, direct MALDI-MS and the combination of the three deposition modes.

When the number of peptides identified with the three techniques is compared, CE-UV/MALDIMS/MS and NanoLC/MALDI-MS/MS appeared to obtain identical performances and are superior 
to direct MALDI-MS. While the direct MALDI-MS analysis allowed the identification of 45 peptides, CE-MS/MS analysis and NanoLC-MS/MS analysis resulted respectively in the identification of a total number of 154 different peptides ranging from 1 (Ins) to 55 (BSA) corresponding to average sequence coverage of $64.1 \%$, and in the identification of a total number of 161 different peptides ranging from 1 (Cyt c) to 68 (BSA) corresponding to average sequence coverage of $60.8 \%$, with a mass accuracy of $20 \mathrm{ppm}$ in MS and $0.5 \mathrm{Da}$ in MS/MS. These results confirmed the usefulness of integrating a separation step prior to MS analysis. The results of the combination of the three deposition modes (Table 1) show a significant improvement of the total number of identified peptides, and of the average sequence coverage. Furthermore, we represented the merger of peptides from CE-MS/MS, NanoLC-MS/MS and direct MALDI-MS analysis (Fig. 3). Results from the Venn comparison clearly show that CE-UV/MALDI-MS/MS and NanoLC/MALDI-MS/MS were complementarity methods at the peptide level with an increase of $42 \%$ in terms of unique identified peptides from 161 (NanoLC analysis only) to 276 (NanoLC and $\mathrm{CE}$ analysis). This complementarity also was useful for improvement of sequence coverage (Table 1). Using the combination of both NanoLC and CE analysis, we obtained an average sequence coverage of $75.9 \%$ as compared to $60.8 \%$ for single NanoLC analysis. This represented an increase of $20 \%$ in terms of average sequence coverage. This resulted in more confident protein identification.

Due to the ability of CE to separate a wide variety of peptides regardless of their chemical nature, these results unambiguously show the possibility of using CE-UV/MALDI-MS/MS to perform MS/MS peptide mapping characterization. Moreover, the automated setting up of a dried droplet deposition protocol which is essential in MALDI for MS/MS acquisition in the case of complex protein mixture, demonstrate the fully compatibility of the system for peptide mapping approach. 


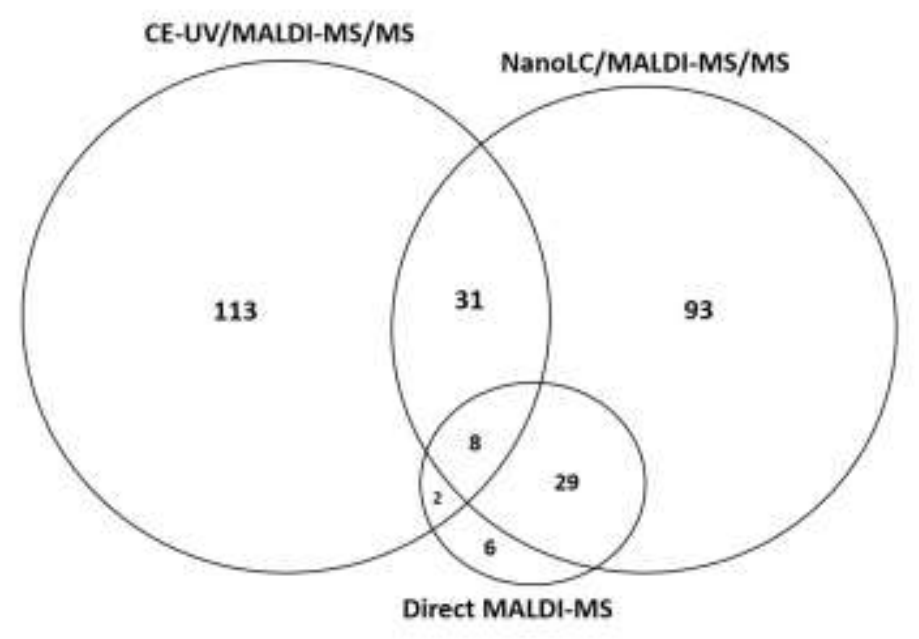

\section{Figure 3.}

Venn comparisons representing the overlap of identified peptides by CE-UV/MALDI-MS/MS, NanoLC/MALDI-MS/MS and direct MALDI-MS. Data originate from Table 1.

\subsection{Analysis of mAb using CE-UV/MALDI-MS/MS.}

mAbs are tetrameric glycoproteins having molecular mass of approximately $150 \mathrm{kDa}$. They are composed of two heavy chains (HC) and two light chains (LC) linked to each other by several disulfide bonds. This type of compounds presents a large number of microheterogeneities commonly found in proteins such as PTMs including glycosylations and small chemical modifications [52]. In this work we performed the analysis of a model commercially marketed humanized $\mathrm{mAb}$ following two strategies: the separation of intact $\mathrm{mAb}$ and the peptide mapping approach both using CE-UV/MALDI-MS interface.

The use of capillary zone electrophoresis (CZE) as a tool for the analysis of charge heterogeneity of intact therapeutic mAbs was investigated by several groups [53-55]. However, due to the drastic condition in terms of salt concentration, no MS detection have been investigated. Indeed, CZE separation of intact proteins is highly affected by the $\mathrm{pH}$ and the ionic strength of the BGE. This represent a major drawback especially for the ESI-MS detection. Due to a greater tolerance to the presence of salts [22], MALDI-MS represent a good alternative. To demonstrate the CEUV/MALDI-MS/MS fraction collection approach, an intact model humanized mAb has been considered. These experiments have been performed following the optimized condition described by the group of Dr. Ruesch [53]. BGE contained $400 \mathrm{mM}$ EACA-acetic acid, $0.05 \% \mathrm{~m} / \mathrm{v}, \mathrm{pH} 5.7$ has been used. He et al. demonstrated the influence of the $\mathrm{pH}$ and the EACA concentration on the 
$\mathrm{mAb}$ separation. As charge variants of mAbs have different acid-base dissociation constants but similar Stokes' radii, $\mathrm{pH}$ buffer has to be selected such that the analytes exhibit significant relative difference in charge, increasing relative difference in electrophoretic mobility. Concerning EACA concentration, they demonstrated that increasing EACA concentration may improve separation efficiency and resolution. To avoid any protein adsorption to the capillary wall, HPC neutral capillary coated has been performed [55]. In addition, concentrated EACA buffer also was used to suppress protein adsorption to the capillary wall and to interact with residual silanol groups that are not covered by HPC [53]. According to electropherogram represented Fig. 4a, tip was positioned in the external BGE vial placed on the Proteineer FC (Bruker Daltonics, Bremen, Germany) for $45 \mathrm{~min}$ then fraction collection began with spotting intervals of $30 \mathrm{~s}$. Fig. $4 \mathrm{~b}$ represent the reconstruction of the separation using MS spectra of each fractions.
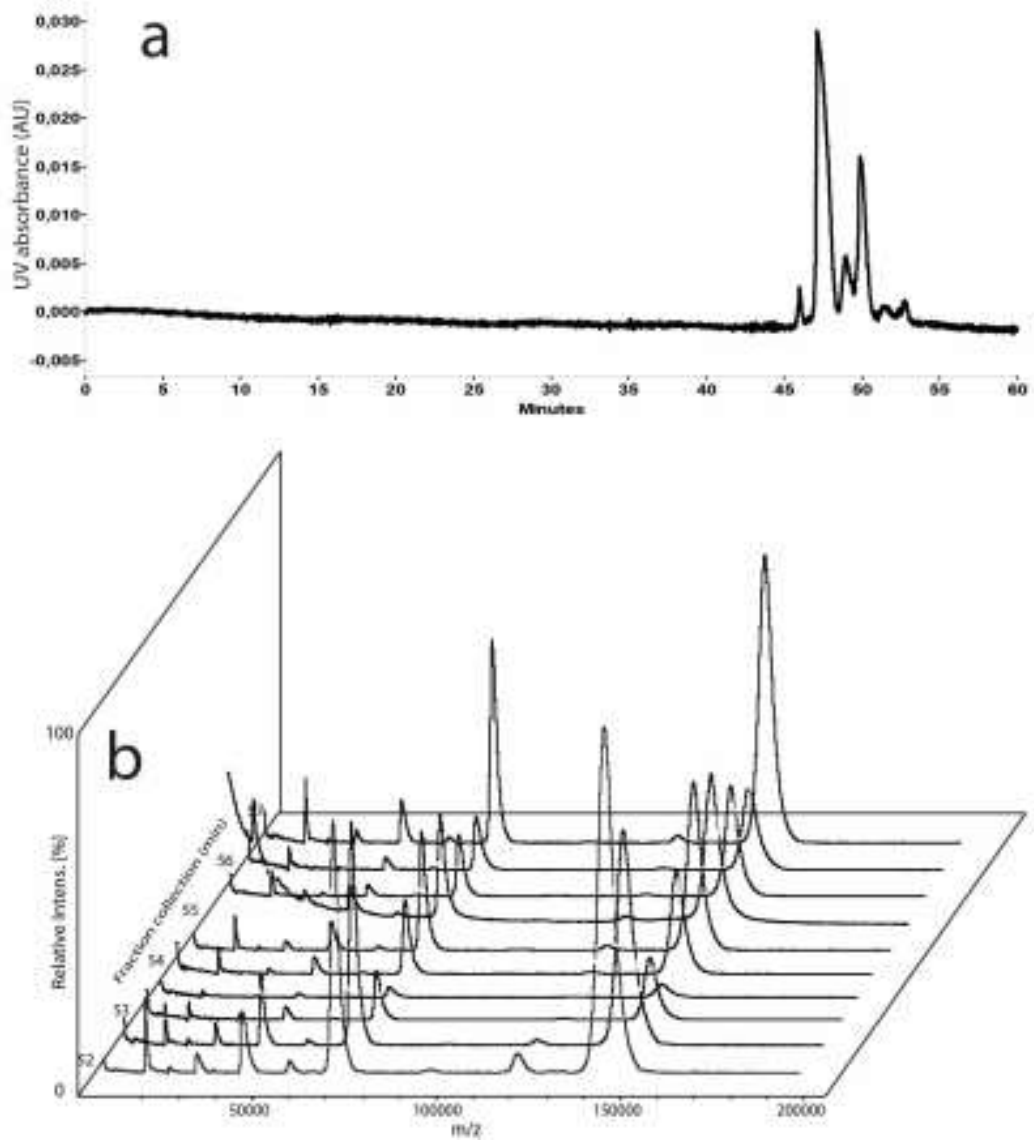

\section{Figure 4.}

UV Electropherogram (a) and corresponding MS spectra of each fraction (b) of intact mAb charge variants by CE-UV/MALDI-MS. Experimental conditions: HPC coated capillary, $50 \mu \mathrm{m}$ d.i. x 80 cm (detection cell, $70 \mathrm{~cm}$ ); BGE: $400 \mathrm{mM}$ EACA-acetic acid, 0.05\% m/v, pH 5.7; Voltage: $30 \mathrm{kV}$; 
Temperature: $25^{\circ} \mathrm{C}$; UV Detection: $200 \mathrm{~nm}$; Injection: 2 psi, $30 \mathrm{~s}$; Sample: $\mathrm{mAb}$ at $4 \mathrm{~g} / \mathrm{L}, \mathrm{MS}$ Experimental conditions: See Experimental.

First of all, these experiments showed the availability of the MALDI-MS to detect intact mAb using highly salted conditions. Moreover, the CE/MALDI-MS profile (Fig. 4b) confirms the good agreement between the UV detection and the deposition time. This confirm the absence of carryover effect and diffusion phenomenon. Unfortunately, limitation of MALDI-MS resolution for molecules up to $100 \mathrm{kDa}$ does not allow to measure the exact mass of the charge variants and then to characterize these glycoproteins. But this study is the proof of principle of the first analysis of intact $\mathrm{mAb}$ charge variants by CZE using a MS detection. This opens new pathways on the characterization of intact mAbs by CE-MS such as fraction collection, enrichment or Top-down approach.

The second strategy consisted to characterize mAb by bottom-up approach. As discussed previously, peptide mapping is commonly used to determine protein amino acid sequence. Moreover, this method allows to locate and/or quantify post translational modification (PTM). This methodology is quite important in early development of therapeutic antibodies as well as during long term life cycle management of the biopharmaceutical products. As part of this work, one of the objective was to investigate the peptide mapping of the same model humanized $\mathrm{mAb}$ by CEUV/MALDI-MS/MS. A sample of mAbs was digested with trypsin enzyme following the same protocol previously described. Fig. 5a shows a separation obtained for the tryptic digest of $\mathrm{mAb}$ (500 fmol injected). The total duration of the separation was less than 50 minutes with a detection window of 20 minutes between 25 and 45 minutes.

In this work, peptide identification was automated and based on MS/MS data meaning that identification was performed on parent ion mass measure and fragment identification. Results of Mascot search showed sequence coverage of $92 \%$ for the $\mathrm{HC}$ and $100 \%$ for the $\mathrm{LC}$ of $\mathrm{mAb}$ corresponding to a total of 92 unique identified peptides (Fig. 5b). Some peptides were selected and fragmented several times during the analysis leading to the same identification. These phenomenon reinforce the confidence of the identification by enabling peptide overlapping.

$\mathrm{mAbs}$ are heterogeneous by nature due to different structural modification which may experience the protein during the lifetime. Those modifications can be Critical Quality Attributes (CQA) as 
they can change the protein conformation and therefore influence the antibody activity. mAb glycosylations represent a class of PTM which can significantly influence its structure, immunogenicity and stability [56]. Results obtained on the same set of data allowed to characterize the 4 major N-Glycosylation carried by the mAb (G0F, G1F, G2F and Man5). As expected by the work of Gahoual et al. [5], we detected glycans still linked to the corresponding peptide backbone of the $\mathrm{HC}$ and we confirmed the ability of $\mathrm{CE}$ migration mechanism to separate glycopeptides having a difference of only one galactose (Fig. 5a). The glycopeptide were detected between 34.1 and $36.1 \mathrm{~min}$. Fig. 5c represents the MS/MS fragmentation spectra of the glycopeptide bearing G1F. As expected, product ions observed in MS/MS mainly correspond to the fragmentation of the glycan moiety. Study of the fragmentation spectra allowed to deduce the structure of the glycan G1F.

Such advanced characterization of digested $\mathrm{mAb}$ peptide mixture in a 50 min analysis shows the potential of CE-UV/MALDI-MS/MS as a fast and sensitive method in mAb characterization.
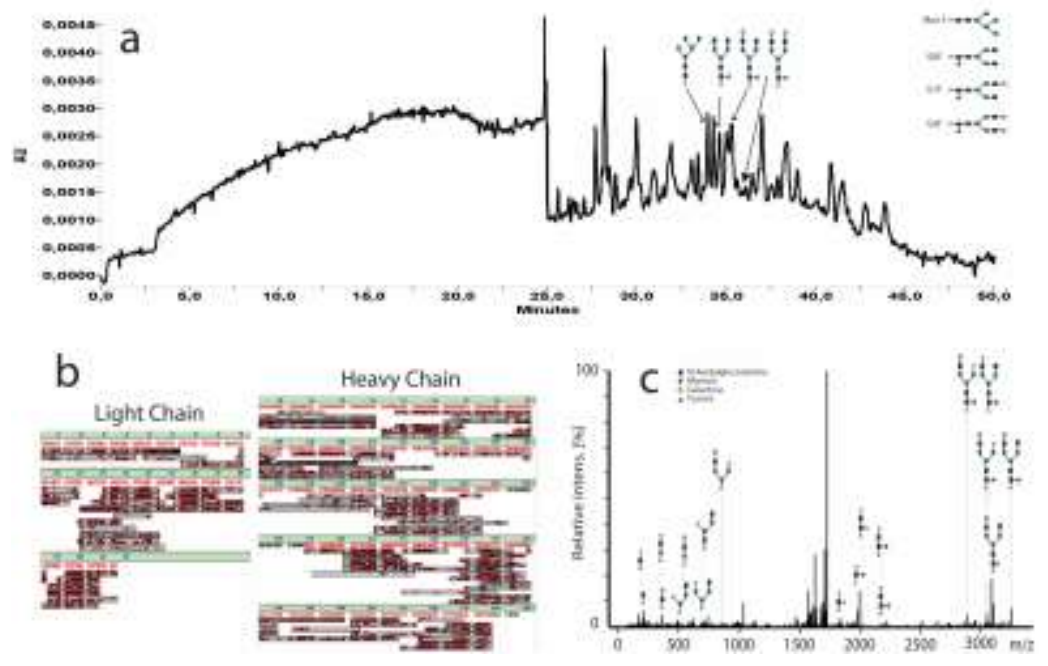

\section{Figure 5.}

UV Electropherogram corresponding to the analysis by CE-UV/MALDI-MS/MS of mAb tryptic digest (a), Sequence coverage obtained for $\mathrm{mAb}$ HC and LC (b) and MS/MS fragmentation spectra of G1F glycopeptide (c). CE Experimental conditions and MS Experimental conditions: See Table 1 and Experimental.

\section{Conclusion}


On this work, we have developed the first automated off-line CE-UV/MALDI-MS/MS with integrated delivery matrix system. The system is based on different homemade modifications performed on a $\mathrm{P} / \mathrm{ACE} \mathrm{MDQ}^{\mathrm{TM}} \mathrm{CE}$ system (Beckman Coulter, Brea, CA) and a Proteineer FC automatic spotting device (Bruker Daltonics, Bremen, Germany). In order to control the CE separation, the original set up of the UV cell in the CE apparatus was deported to allow the simultaneous UV detection near the outlet of the capillary and fraction collection. In order to reduce the total capillary length, the spotting device was modified with a shift of the original steel needle close to the CE output. Minimum total capillary length can be $60 \mathrm{~cm}$. Finally, in order to be universally compatible in terms of MALDI deposition modes, a homemade delivery matrix system was developed. Neutral coated capillary can therefore be used for the achievement of intact protein or peptide separation. The evaluation of the system on the separation of five proteins showed the acquisition of electropherograms with high resolution and high repeatability. Migration times allow defining the window of fraction collection, and assessing time interval for each spot. Concerning peptide mapping approach on a nine digested proteins mixture, 154 unique identified peptides were

characterized using MS/MS spectra corresponding to average sequence coverage of $64.8 \%$. On the basis of the results obtained and as compared to NanoLC/MALDI-MS/MS, CE-UV/MALDIMS/MS can be considered as a complementarity methods to conventional LC-MALDI/MS especially to improve the confidence in protein identification. Finally, this system has been used for the characterization of a humanized $\mathrm{mAb}$ following intact protein separation and peptide mapping strategies. In spite of the lack of resolution of the MALDI-MS, this work represents the first analysis of intact mAb charge variants by CZE using a MS detection and opens new ways of research for the characterization of intact mAbs. Moreover, the CE-UV/MALDI-MS/MS fragmentation allowed $100 \%$ sequence coverage of the LC and $92 \%$ on the HC and the separation of the 4 major glycosylated peptides and their structural characterization in the same analysis data set. These results analysis demonstrates the power of CE-UV/MALDI-MS/MS as a sensitive method in $\mathrm{mAb}$ characterization and more generally in bottom-up proteomic approach.

\section{Acknowledgments}

Michael Biacchi would like to thank the ANFH for funding his Ph.D work. LSMIS would like to thank Dr. Bernard Capolaghi (Hopital Bel Air, Thionville) for his support. LSMIS would like to thank Paape Rainer, Pierre-Olivier Schmit and Anja Resemann from Bruker for their help. The 
authors would like also to express their gratitude Dr. E. Wagner-Rousset, Dr. D. Ayoub, MC. JaninBussat, O. Colas (Centre d'immunologie Pierre Fabre, St Julien en Genevois, France) and Rabah Gahoual (LSMIS, Strasbourg, France) for helpful discussions around antibody structural characterization. Dr. Yannis François would like to thank Dr. Jean-Marc Busnel for very fruitful discussions. 


\section{References}

[1] Skalnikova, H.K. Biochimie 2013, 95 (12), 2196-2211.

[2] Ma, N., Ling, R., Zaidah, L., Su, S. Int. J. Mol. Sci. 2013, 14 (4), 7515-7541.

[3] Gahoual, R., Busnel, J.M., Wolff, P., Francois, Y.N., Leize-Wagner, E. Anal. Bioanal. Chem. 2014, 406, 1029-1038.

[4] Beck, A., Sanglier-Cianférani, S., Van Dorsselaer, A. Anal. Chem. 2012, 84, 4637-4646.

[5] Gahoual, R., Burr, A., Busnel, J.M., Kuhn, L., Hammann, P., Beck, A., François, Y.N., LeizeWagner, E. $m A b s$ 2013, 5 (3), 479-490.

[6] Beck, A., Wurch, T., Bailly, C., Corvaia, N. Nat Rev Immunol. 2010, 10, 345-352.

[7] Reichert, J.M. mAbs 2012, 4(3), 413-415.

[8] Wang, W., Singh, S., Zeng, D. L., King, K., Nema, S. J. Pharm. Sci. 2007, 96, 1-26.

[9] Aebersold, R., Mann, M. Nature 2003, 422, 198-207.

[10] Krylov, S.N., Dovichi, N. Anal. Chem. 2000, 72, 111R-128R.

[11] Kasicka, V. Electrophoresis 2010, 31, 122-146.

[12] El Rassi, Z. Electrophoresis 2010, 31, 174-191.

[13] Smith, R.D., Udseth, H.R. Nature 1988, 331, 639-640.

[14] Rose, D.J., Jorgenson, J.W. J. Chromatogr. A 1988, 438, 23-34.

[15] Ahmed, F.E. J. Chromatogr. B 2009, 877, 1963-1981.

[16] Faserl, K., Sarg, B., Kremser, L., Lindner, H. Anal. Chem. 2011, 83, 7297-7305.

[17] Ramautar, R., Mayboroda, O.A., Somsen, G.W., de Jong, G.J. Electrophoresis 2011, 32, 5265.

[18] Haselberg, R, de Jong, G.J., Somsen, G.W. Journal of Chromatography A 2007, 1159, 81109.

[19] Haselberg, R., de Jong, G.J., Somsen, G.W. Electrophoresis 2013, 34, 99-112.

[20] Ramautar, R., Heemskerk, A.A.M., Hensbergen, P.J., Deelder, A.M., Busnel, J.M., Mayboroda, O.A. J. Proteomics 2012, 75, 3814-3828.

[21] Smith, R.D., Olivares, J.A., Nguyen, N.T., Udseth, H.R. Anal. Chem. 1988, 60, 436-441.

[22] Hommerson, P., Khan, A.M., de Jong, G.J., Somsen, G.W. Mass. Spectrom. Rev. 2011, 30, 1096-1120.

[23] Wachs, T., Sheppard, R.L., Henion, J. J. Chromatogr. B Biomed. Appl. 1996, 685, 335-342.

[24] Zhu, G., Sun, L., Yan, X., Dovichi, N. Anal. Chem. 2013, 85, 2569-2573. 
[25] Moini, M. Anal. Chem. 2007, 79, 4241-4246.

[26] Busnel, J.M., Schoenmaker, B., Ramautar, R., Carrasco-Pancorbo, A., Ratnayake, C., Feitelson, J.S., Chapmann, J.D., Deelder, A.M., Mayboroda, O.A. Anal. Chem. 2010, 82, 94769483.

[27] Chang, S.Y., Yeung, E.S., Anal. Chem. 1997, 69, 2251-2257.

[28] Murray, K.K., Mass. Spectr. Rev. 1997, 16, 283-299.

[29] Mechref, Y., Capillary Electrophoresis and Microchip Capillary Electrophoresis: Principles, Applications, and Limitations, Wiley, 2013, 367-380.

[30] Preisler, J., Hu, P., Rejtar, T., Karger, B.L. Anal. Chem. 2000, 72, 4785-4795.

[31] Preisler, J., Foret, F., Karger, B.L. Anal. Chem. 1998, 70, 5278-5287.

[32] Musyimi, H.K., Narcisse, D.A., Zhang, X., Stryjewski, W., Soper, S.A., Murray, K.K. Anal. Chem. 2004, 76, 5968-5973.

[33] Amon, S., Plematl, A., Rizzi, A. Electrophoresis 2006, 27, 1209-1219.

[34] Lechner, M., Seifner, A., Rizzi, A. Electrophoresis 2008, 29, 1974-1984.

[35] Silvertand, L.H.H., Sastre Toraño, J., de Jong, G.J., van Bennekom, W.P. Electrophoresis 2009, 30, 1828-1835.

[36] Weiss, N.G., Zwick, N.L., Hayes, M.A. J. Chromatogr. A 2010, 1217, 179-182.

[37] Johnson, T., Bergquist, J., Ekman, R., Nordhoff, E., Schürenberg, M., Klöppel, K.D., Müller, M., Lehrach, H., Gobom, J. Anal. Chem. 2001, 73, 1670-1675.

[38] Wang, J., Ye, H., Zhang, Z., Xiang, F., Girdaukas, G., Li, L. Anal. Chem. 2011, 83, $3462-$ 3469.

[39] Bachmann, S., Bakry, R., Huck, C.W., Polato, F., Corradini, D., Bonn, G.K. Electrophoresis 2011, 32, 2830-383.

[40] Hanton, S.D., Hyder, I.Z., Stets, J.R., Owens, K.G., Blair, W.R., Guttman, C.M., Giuseppetti, A.A. J. Am. Soc. Mass. Spectr. 2004, 15, 168-179.

[41] Vannatta, M.W., Whitmore, C.D., Dovichi, N.J. Electrophoresis 2009, 30, 4071-4074.

[42] Wang, J., Ma, M., Chen, R., Li, L., Anal. Chem. 2008, 80, 6168-6177.

[43] Busnel, J.M., Josserand, J., Lion, N., Girault, H.H. Anal. Chem. 2009, 81, 3867-3872.

[44] Li, Y., Yun, B., Deng, C., Tang, J., Liu, J., Zhang, X. Proteomics 2007, 7, 3661-3671.

[45] Bi, H., Qiao, L., Busnel, J.M., Devaud, V., Liu, B., Girault, H.H. Anal. Chem. 2009, 80, 1177 1183. 
[46] Luo, Y.Q., Xu, S.Y., Schiling, J.W., Lau, K.H., Whitin, J.C., Yu, T.T.S., Cohen, H.H. JALA, 2009, 14, 252-261.

[47] Liu, J., Tseng, K., Garcia, B., Lebrilla, C. B., Mukerjee, E., Collins, S., Smith, R. Anal. Chem. 2001, 73, 2147-2151.

[48] Xu, Y., Little, M.W., Murray, K.K. J. Am. Soc. Mass Spectrom. 2006, 17, 469-474.

[49] Shen, Y., Smith, R.D. J. Microcolumn. Sep. 2000, 12, 135-141.

[50] Busnel, J.M., Lion, N., Girault, H.H. Electrophoresis 2008, 29, 1565-1572.

[51] Pourhaghighi, M.R., Busnel, J.M., Girault, H.H. Electrophoresis 2011, 32, 1795-1803.

[52] Walsh, G., Jefferis, R. Nat. Biotech. 2006, 24, 1241-1252.

[53] He, Y, Lacher, N.A., Hou, W., Wang, Q., Isele, C., Starkey, J., Ruesch, M. Anal. Chem. 2010, $82,3222-3230$.

[54] He, Y., Isele, C., Hou, W., Ruesch, M. J. Sep. Sci. 2011, 34, 548-555.

[55] Gassner, A.L., Rudaz, S., Schappler, J. Electrophoresis 2013, 34, 2718-2724.

[56] Jefferis, R. Biotechnol. Prog. 2005, 21, 11-16. 